\title{
CASUAL AND BASAL BLOOD PRESSURES I.-IN BRITISH AND EGYPTIAN MEN
}

BY

\author{
G. M. ALAM AND F. H. SMIRK \\ From the Department of Pharmacology, Egyptian University, and the Department of Medicine, University of \\ Otago, New Zealand \\ Received June 1, 1943
}

In the course of clinical investigations on healthy Egyptian men, we observed that during a period of rest in the sitting posture the systolic blood pressure often fell below 90 and usually below $100 \mathrm{~mm}$. of mercury. This led to a study of the blood pressures of British subjects resident in Egypt and of others resident in London. The pressure found under the conditions described below is called basal* blood pressure because it was not found possible to reduce it appreciably below this level by rest or sleep. Our observations in a physiological type of low blood pressure may be of interest in relation to low blood pressure which is thought to be pathological.

\section{METHOD}

Measurements of the blood pressure were made by the auscultatory method, either with manometers in which the whole of the mercury column was visible, or with those of the Baumanometer type which had been checked by an ordinary mercury manometer. The diastolic pressure was taken at the moment when the arterial sound becomes muffled, usually $5 \mathrm{~mm}$. higher than that at which the sound disappeared. The blood pressure was measured on the left arm with the subject sitting in a quiet, warm room. All subjects were instructed to find a comfortable posture, and then to remain still and with the mind blank throughout the half-hour or longer period during which the measurements were made. No conversation was allowed. The observer avoided unnecessary movement, and as a rule no third person entered the room during this time. To allay apprehension the subjects were informed that the investigation would be confined to the repeated measurement of blood pressure. Most subjects became somnolent but in general did not sleep.

The blood pressure was measured as frequently as possible during the first three minutes after adopting the sitting posture. Blood pressure readings were then taken every few minutes throughout the half-hour period of rest, in order to habituate the subject to the procedure of blood pressure measurement. Without habituation of the subject by the continuous presence of the observer and by repeated measurements, the blood pressure falls are less than those we report. Towards the end of the half-hour period the measurements of the blood pressure were made at intervals of about one minute.

\section{RESULTS}

In Fig. 1 are recorded systolic blood pressures and in Fig. 2 diastolic pressures. The height of a patient's blood pressure, under the stated conditions, is indicated by the distance of the cross from the left-hand side. For each subject three systolic and three diastolic pressures are recorded in the diagrams, namely:

* The term " basal blood pressure" has already been used in the Joint Report of the Committees appointed by the Cardiac Society of Great Britain and Ireland and the American Heart Association, on the Standardization of Methods of Measuring the Arterial Blood Pressure. "In detailed researches on blood pressure the use of a basal pressure might be considered after preparation similar to that used for basal metabolism. It should be determined 10-12 hours after the last meal of the previous night, and after resting half an hour in warmed room."-EDITOR. 


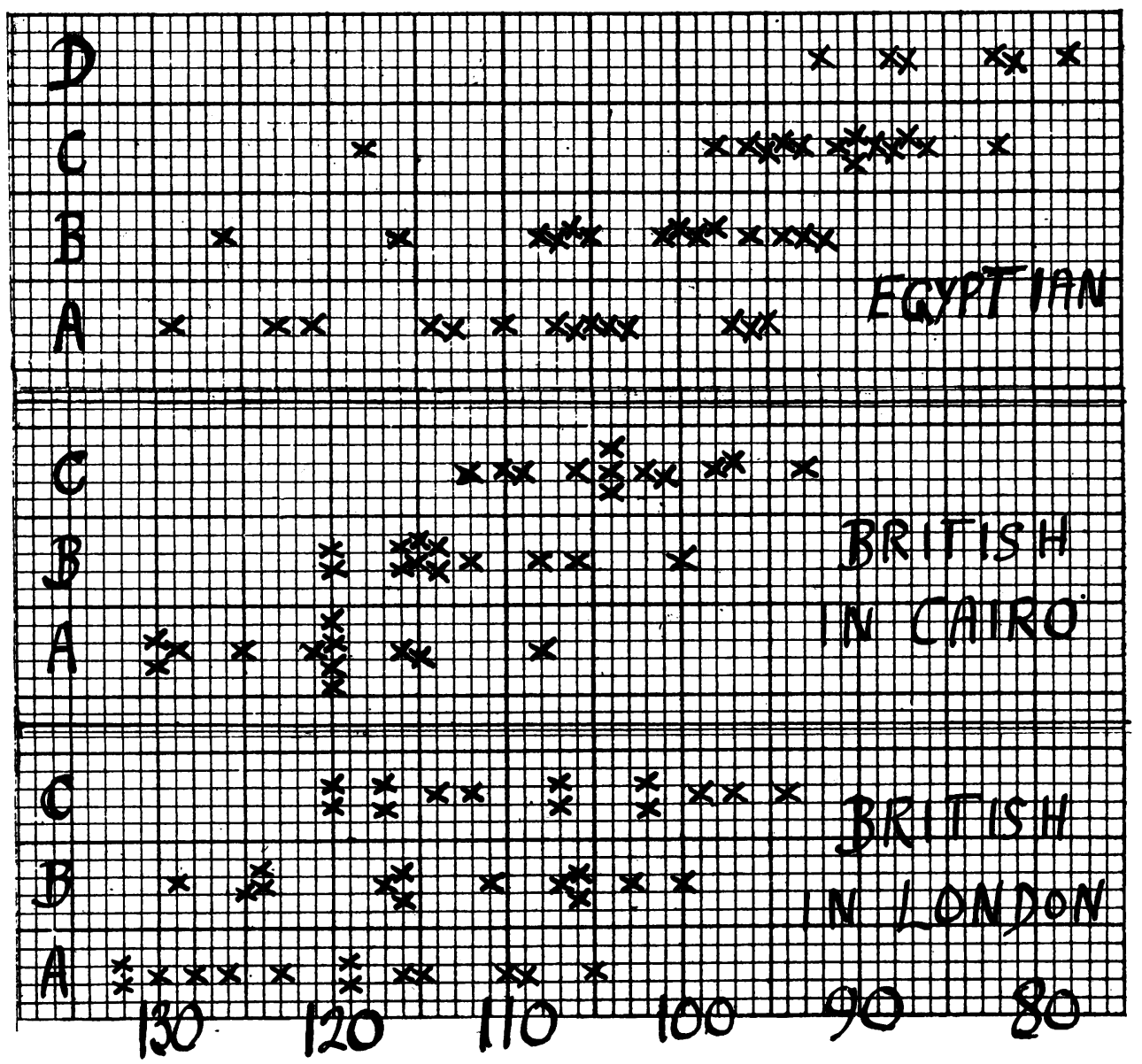

FIG. 1.-Effect of rest and emotional desensitization on the systolic blood pressure in 14 Egyptian nationals (above), in 12 British in Cairo (middle), and in 13 British in London (below). (A) Casual blood pressure. (B) Lowest pressure of the same subjects during the next 3 minutes. (C) Lowest level maintained for three consecutive readings during 30 minutes. (D) Level attained after 90 minutes. Details of the procedure followed during this period are set out under " Method."

(A) The casual blood pressure, which was measured soon after the patient entered the room and was seated;

(B) The lowest pressure measured in the next three minutes; and

(C) The basal blood pressure, which was the lowest level of the blood pressure that was maintained for three consecutive readings during the half-hour period of rest and habituation of the subject to the presence of the observer and to the procedure of blood pressure measurement.

The average levels of the systolic and diastolic pressure do not differ appreciably in the two British groups, but there is an evident difference between these and the Egyptian group. Casual blood pressures are lower and basal pressures are much lower in Egyptian nationals, approximately half the basal systolic pressures lying between 80 and $90 \mathrm{~mm}$., and half the diastolic pressures between 50 and $57 \mathrm{~mm}$. (Fig. 1 and 2).

The blood pressure measurements on British nationals in London were made during a hot, moist August. The pressures of British residents in Egypt and of the Egyptians were measured in Cairo, mostly in April and May, with a higher temperature and lower humidity than London in August. The Egyptian subjects referred to above were of the poorer classes, but the low pressures encountered were not due to malnutrition, since equally low pressures were observed also in well-nourished Egyptian students and doctors of a similar age group. These observations are supported by a considerable number of blood pressure readings made 


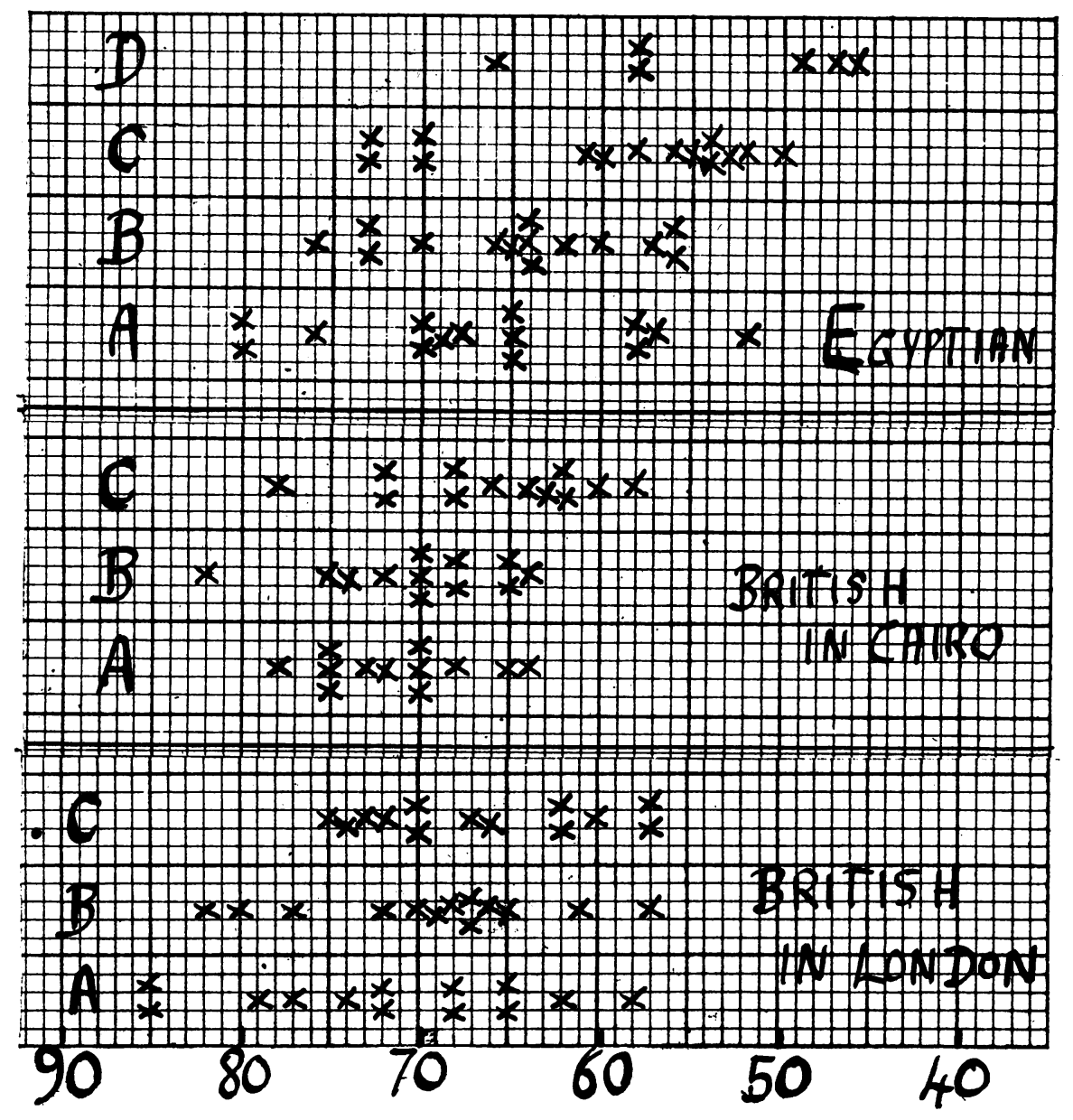

FIG. 2.-Effect of rest and emotional desentitization on the diastolic blood pressure in British and Egyptian nationals. (A), (B), (C), and (D) as in Fig. 1.

in the course of clinical investigations on patients without disease of the cardiovascular system. There seems no doubt that, under comparable conditions, both richer and poorer classes of Egyptians, whether heavy meat eaters or vegetarians, have lower blood pressures, especially basal pressures, than the British, and this difference is not explained to any great degree by the character of the food or by other differences in the environment. Arterial hypertension is, nevertheless, a frequent condition among in-patients in Egyptian hospitals.

The average of the casual blood pressures and of the basal blood pressures in young British and Egyptian nationals are set out in Table 1.

\begin{tabular}{lccr} 
& TaBLE I & \multicolumn{2}{c}{ Average Blood Pressures } \\
& $\begin{array}{c}\text { Number } \\
\text { studied }\end{array}$ & Casual & Basal \\
British & 25 & $121 / 71$ & $106 / 67$ \\
Egyptian & 14 & $110 / 66$ & $91 / 59$
\end{tabular}

\section{DisCUSSION}

It is well recognized that the blood pressure is variable and is raised by emotion. In the many statistical studies concerned with the level of the blood pressure in health the figure recorded is for the casual blood pressure, in that usually few precautions are taken to guard against the pressor effects of emotion. 
The normal European systolic pressure during sleep is of the order of $95 \mathrm{~mm}$. of mercury (Müller, 1921; Brooks and Carroll, 1912). Some of the above observations were made during natural sleep, and in others sleep was induced by hypnotics such as sodium barbitone. In British subjects, the average basal systolic blood pressure with the subjects awake is about 106 , which is 5 to $10 \mathrm{~mm}$. higher than the reported average levels of the systolic pressure attained after some hours of sleep. If the patients fell asleep during the investigation no appreciable difference between the waking and sleeping pressures was noted. The possibility that the blood pressure falls further if sleep continues has not been studied. In a few Egyptians the measurements of blood pressure was continued for a period of three hours and further falls of blood pressure occurred; in five out of six the systolic blood pressure fell below 90 and in one to 78; in no case did any symptom develop.

The observer and his sphygmomanometer represent a stimulus that raises the blood pressure, and emotional habituation to both is required before a low level of the pressure is obtained. There is a widespread recognition of the variability of the blood pressure in health, and it is commonly stated that the figure which should be recorded is the lowest attained under conditions of rest. The pressures usually recorded under conditions of rest lie, with few exceptions, within the range of what is commonly regarded as normal. A considerable proportion, however, of our measurements made in healthy subjects at rest but with deliberate emotional desensitization, fall to levels commonly thought to be pathological (below 110-100, according to various authors).

In general, basal blood pressures cannot be obtained by repeated measurements made in a hospital ward, with or without screens about the bed; nor in subjects who suspect that the blood pressure measurements are only a prelude to further procedures. The environment of the subject must be entirely unstimulating. Restlessness on the part of the observer, noises outside the room, and displays of medical equipment may invalidate the result. In other words, observations on man require experimental conditions similar to those which Pavlov (1927) found essential in his conditioned reflex experiments on dogs. Emotional desensitization of the human subject by continued repetition of the stimulus and avoidance of new and especially of unfamiliar stimuli, bears a close resemblance to some of the experiments of the Pavlov school on conditioned inhibition in the dog.

Sometimes the blood pressure fell to a level which, encountered in surgical shock would indicate a dangerous condition. Under physiological conditions such low blood pressure is rarely observed with casual measurements. The difference between the casual and basal blood pressures varies considerably with different subjects. It may well be that many patients considered to be examples of hypotension have a normal basal blood pressure, but sub-average degrees of elevation of the casual above the basal pressure.

\section{SUMMARY}

Egyptian men resident in Egypt have much lower blood pressures than British men resident either in Egypt or in England. This difference does not depend upon differences of temperature, diet, or social status.

Half an hour of rest in the sitting posture, together with deliberate emotional desensitization to the presence of the medical examiner and to the procedure of blood pressure measurement reduced the systolic blood pressure to below 100 in 13, and to below 90 in 5 out of 14 Egyptian men; and to below 105 in 13, and to below 100 in 6 out of 25 British men.

Such lowering of the blood pressure was not associated with any symptoms.

\section{REFERENCES}

Brooks, H., and Carroll, J. H. (1912). Arch. intern. Med., 10, 97.

Müller, O. (1921). Acta Med. Scand., 55, 381.

Pavlov, I. P. (1927). Conditioned Reflexes, English edition, Oxford. 